\title{
REFLECTIONS
}

\section{Women in Medicine and the Ticking Clock}

\author{
Lisa N. Miura, $M D^{1}$ \\ Rebecca S. Boxer, MD, MS \\ ${ }^{1}$ Oregon Health and Science University, Portland, \\ Oregon
}

${ }^{2}$ Case Western Reserve University, Cleveland, Obio

\begin{abstract}
Our careers began with the long, arduous, and intensely focused commitments of premed, medical school, residency, and fellowship. We planned our lives rationally and enacted our plans with care. Now we have long-desired and satisfying careers. We discovered something, however, that the culture of medical training and our plans had failed to anticipate: We did not allow time for the unexpected.
\end{abstract}

Ann Fam Med 2013;381-382. doi:10.1370/afm.1515.

$\mathrm{F}$ or us, the unexpected came in the form of consequences from delayed childbearing. We had felt immune to failure at childbearing, as if the possibilities of infertility and loss did not apply to us; we were different. We were weeded out from the day we hit freshman biology. We were graced with the full support of families, professors, and peers. There was barely a mention that we might not have it all; that, as we toiled, we were choosing to gamble our fertility-gambling more than the ability to become pregnant; gambling the ability to deliver a healthy child.

As many women pursuing medical careers have done, we put the dream of motherhood on the wait list. We waited for the perfect moment: a time when we were settled-training complete, career launched, financial stability attained. Only then did we allow ourselves to begin our families.

But neither the biological clock nor complications with pregnancies were going to wait for career success. At key points, each of us arrived at the woeful realization that motherhood might prove elusive. Looking back, we are impressed with our naiveté, the effects it had on our decisions, and the powerful lessons that affect our practices today.

Postponing motherhood can result in unintended childlessness, the need for assisted reproductive techniques, adoption, or having a smaller than desired family size. As Ann-Marie Slaughter discusses in Why Women Still Can't Have It All, "the most important sequencing issue is when to have children."1

We hope to raise issues for our profession. Our hard-won understandings hold important lessons for training and practice. Here are our stories:

L.N.M.: I almost lost the chance of having my own child. The years passed by more swiftly than I realized. At 38, my specialist's deflating words of "infertility due to advanced maternal age" left me in disbelief. His graph illustrated the steep decline in fertility each year after 35 . Although aware, I underestimated my risk. I made efforts to maintain optimal health, avoid toxins, and stay positive. How could his words apply to me? It seemed I knew numerous women, along with many celebrities, who had children in their late 30s and early 40s. The biological clock: I thought I could beat it. Why did I believe, as a physician, I was immune to infertility?

R.S.B.: In 2002, I sat in a hospital bed, post cesarean section, with my deceased infant son in my arms, flabbergasted that this could happen to me. A stillborn child does not happen to a physician! I had prenatal care! I don't drink or smoke! I have no chronic illnesses! I waited to be awakened from the nightmare. I am a healthy woman who is on top of my game. When I work hard, success is always delivered. Not this time. And not the 2 previous times, which had ended in miscarriage. There I sat at 32, desperate for a child and unable accomplish what came so easily to so many other women. 
L.N.M.: I knew little about fertility, being trained as an internist and geriatrician. As I sat in the clinic, feeling a bit sheepish in this new milieu, I noted other familiar faces. I learned that countless female professionals endure the same experience-delaying motherhood too long and requiring the need for costly, even painful procedures, to conceive. Going through the fertility process was like being on a never-ending roller coaster. It was an emotional 3 years of heartache and disappointment. I felt my dream slipping away with the arrival of each birthday. And despite having fairly good incomes, the cost of in vitro fertilization (IVF) was taking its toll-tens of thousands of personally-financed dollars. After 3 failed IVF cycles, we were advised to consider donor eggs or adoption. I was devastated to think that I lost my chance at having my own biological child.

R.S.B.: I can barely remember my first year of fellowship after I delivered my stillborn child. I was so completely and utterly devastated by what had occurred and the profound disappointment that I might never become a parent. I never imagined that having children would be such a struggle. Although at 32 years I was still young enough to keep trying, the emotional and physical toll was great. I was terrified that my time would run out as each pregnancy ended in heartbreak.

If we had it to do over, we would grant our biological clocks and the goal of having children a more integral role in our life plans. We were fortunate-though it was not easy-and are now doctors with children.

L.N.M.: Determination to pursue my dream finally brought the exciting news we so desired to hear. At the time, I was hospitalized for a complication of IVF, ovarian hyperstimulation syndrome. My hCG level was elevated, a hopeful sign. Though the pregnancy was relatively uneventful, it ended with a complicated, premature birth at 35 weeks by emergency cesarean delivery. But into my arms at the age of 40 years came the unbelievable gift of a healthy baby boy. He is the true joy of my life. Ultimately, it took 2 miscarriages and 4 IVF cycles to have our son.

R.S.B.: Eventually I was gifted with a baby girl and soon after a baby boy. I realized now that I was lucky. Lucky to have these 2 healthy children. I have colleagues who never had any, some by choice and some by circumstance. Having children was much rougher than I had ever imagined.

Our experiences are not unique; some of the most profound and difficult experiences for women surround childbearing. As women in medicine, however, we had a tendency to detach ourselves from typical life. Now we understand that we all face a share of the unexpected, whether it arrives in the form of a delay in finding the right partner or other circumstances that affect the best of human planning. Now we know that a more realistic awareness of our own vulnerabilities can expand how we understand and practice medicine.

R.S.B.: After about a year, I had recovered from the devastation. I wasn't crying every day; I could focus and think again, and I was a changed person. I learned the true meaning of compassion. The loss of my child made me a better physician. I can cry and celebrate with my patients in a way that I never could before. I understand what it means to overcome adversity and to count your blessings every day.

I have spoken to many women about my loss, and surprisingly many have also lost babies. Women in their 90s who have had a stillbirth are still brought to tears telling me about the experience! Interestingly, women I have known for a long time share their story only when I share mine or I ask them directly. Still, few women talk about their childbearing struggles and losses. It is often considered taboo, private, and a marker of vulnerability. Many women suffer loss alone. The isolation and loneliness can be overwhelming and shake the orderly world that many of us have created for ourselves.

As physicians, we need to examine how we aid women through these hard times. We should consider how to better support women who have difficulties conceiving, who are pregnant, or who have lost children. Female physicians should receive our support for pregnancy and not be left to feel ashamed of difficulties or complications with conception or childbirth.

Unfortunately, the culture of medical training can intensify the struggles of those who desire children. Both men and women in medicine should carefully consider how medical school, residencies, and fellowships can impinge on family planning. Women should have an option to work within time frames compatible with fertility, without negatively affecting their careers. Training programs and employers should provide more information and support, and adopt policies that are consistent with the complex lives of today. Overall, there is a dearth of medical literature regarding infertility in women in medicine and family planning during medical training. With a rising percentage of women accepted to medical schools and residency programs (47\% and $46 \%$, respectively, in 2011), these issues will likely become more apparent. ${ }^{2}$

Until then, we know too well the costs of postponing motherhood. No woman should take pregnancy or uncomplicated deliveries for granted.

To read or post commentaries in response to this article, see it online at http://www.annfammed.org/content/11/4/381.

Key words: delayed childbearing; pregnancy complications; maternal age; infertility

Submitted September 12, 2012; submitted, revised, November 27, 2012; accepted, December 12, 2012.

\section{References}

1. Slaughter, AM. Why women still can't have it all. The Atlantic. July/ August, 2012. http://bit.ly/NJYf5f. Accessed Jul 3, 2012.

2. Association of American Medical Colleges. Women in U.S. Academic Medicine and Science: Statistics and Benchmarking Report 2011-2012. Washington, DC: AAMC; 2012:6. 